\title{
El concepto marxista de nación ${ }^{\mathrm{I}}$
}

\author{
Carlos Barros ${ }^{I I}$
}

Resumen: El "problema nacional" resurge en el siglo XXI con gran fuerza y mayor complejidad: nacionalidades de origen medieval, Estados-nación modernos y contemporáneos, fenómenos actuales de agregación global (Europa, mundialización). Abordamos metodológicamente el tema echando mano de los clásicos del materialismo histórico, a partir del olvidado concepto de "condiciones de producción" (económicas, naturales e históricas) y sus aplicaciones a los hechos nacionales tratados por Marx y Engels en el siglo XIX.

Palabras Clave: Identidad, historia, marxismo, nación, nacional, nacionalismo.

\section{The Marxist Concept of Nation}

\begin{abstract}
The "national problem" reappears in the 21st century with great force and greater complexity: nationalities of medieval origin, modern and contemporary nationstates, current phenomena of global aggregation (Europe, globalization). We methodologically approach the subject using the classics of historical materialism, from the forgotten concept of "conditions of production" (economic, natural and historical) and their applications to national events treated by Marx and Engels in the nineteenth century.
\end{abstract}

Keywords: Identity, History, Marxism, Nation, National, Nationalism

Artigo recebido em 18/06/2019 e aprovado em 10/08/2019. 


\section{EL CONCEPTO MARXISTA DE NACIÓN ${ }^{1}$}

\section{CARLOS BARROS}

El marxismo del siglo XX consideró la nación como un "problema" o "cuestión" que había que resolver teórica y políticamente. Urgencia que se agudizó en los momentos de grandes cambios históricos. En las postrimerías del pasado siglo e inicios del siglo XXI, a partir de la Caída del Muro de Berlín primero y de una globalización galopante después, el "problema nacional" resurge con enorme fuerza y mayor complejidad.

En ciencias sociales la fórmula de referencia es ahora "identidad nacional"III, que el marxismo presente ha de asumir por lo que significa. El Diccionario de la Lengua Española, y otros en otras lenguas, contiene entre las acepciones de la palabra 'identidad', tanto "rasgos propios de un individuo o de una colectividad que los caracterizan frente a los demás" como la "conciencia que una persona [o colectividad] tiene de ser ella misma y distinta a las demás", que recuerda de alguna forma la "cosa en sí" y la "cosa para sí" de Hegel y Marx. Lo bueno de transitar de la "cuestión nacional" a la "identidad nacional" es que pasamos del problema a la búsqueda de una solución: un concepto de nación que abarque lo objetivo y lo subjetivo del fenómeno nacional, que hoy por hoy no tiene históricamente fin. Reintroduciendo la base material, natural y económico-social, junto con la conciencia y la política, en la explicación de los hechos nacionales, viejos y nuevos, en la actualidad reducidos con harta frecuencia a las ideas y los sentimientos, sin el rigor y la objetividad de las ciencias del hombre, la sociedad y la historia. Paradójicamente (por el tiempo transcurrido) las obras originales de Marx y Engels pueden, y deben, servirnos de gran ayuda.

Los fundadores del marxismo tuvieron que hacer frente en el Manifiesto comunista (1848) a la crítica de que "los comunistas querían abolir la patria, la nacionalidad", respondieron con tres afirmaciones concatenadas $\left.{ }^{\mathrm{IV}}: 1\right)$ "Los obreros no tienen patria". 2) "El proletariado debe elevarse a clase nacional $\mathrm{V}^{\mathrm{V}}$, construirse a sí mismo en cuanto nación". 3) El proletariado "es nacional, aunque en modo alguno en el sentido que le da la burguesía". Respuesta compleja que compatibiliza internacionalismo y nacionalismo obrero. Apremia restituir este enfoque dialéctico actualizándolo en el tiempo presente, mediante una lectura más detallada de sus obras, rebasando la simplificación de su pensamiento, entre sus adversarios y sus partidarios.

Marx y Engels no dejaron escrita una teoría materialista acabada de la nación. Tampoco en temas que reclamaron más su atención, como las clases sociales y el Estado, encontramos en sus obras un desarrollo conceptual explícito y sistemático. Engels, más preocupado que Marx por las exposiciones didácticas y sintéticas, escribía en los borradores del Anti-Dühring: "El sistematismo, según Hegel, es imposible. Es claro que el mundo es un sistema unitario, es decir, un todo coherente; pero el conocimiento de ese sistema presupone el conocimiento de toda la naturaleza y la historia, conocimiento que los hombres no consiguen nunca"VI . Tuvimos, pues, que reconstruir los conceptos teóricos y metodológicos del marxismo originario partiendo de unos textos extensos y dispersos pero coherentes. Así se ha hecho con mayor o menor fortuna con otras nociones fundamentales del materialismo histórico. Pero no así con el término nación, enfocado por los marxismos posteriores de forma más política e internacional que teórica y nacional ${ }^{\mathrm{VII}}$.

El punto de partida para la recuperación de un concepto originalmente marxista de nación es, sin duda, la noción de condiciones de producción, usada profusamente por Marx y Engels de manera general o particular tanto para teorizar sobre el modo de producción, las fuerzas productivas o las relaciones de producción, como para definir

Cadernos do Tempo Presente, São Cristóvão-SE, v. 11, n. 02, p. 27-35, jul/dez. 2020||

http://www.seer.ufs.br/index.php/tempo 


\section{EL CONCEPTO MARXISTA DE NACIÓN ${ }^{1}$}

\section{CARLOS BARROS}

ámbitos espaciales y comunitarios interclasistas como la nación y otros términos sinónimos o afines (país, pueblo, patria). La noción de condiciones de producción dejó poco a poco de utilizarse a lo largo del siglo XX, en perjuicio singularmente del conocimiento científico del hecho nacional, que perdió así la oportunidad de definirse de manera más profunda, en función más de su base histórico-material que de la ideología y la política, asimismo influyentes.

Marx y Engels heredan de Hegel el concepto de condiciones, entendidas como condiciones previas/condiciones resultantes: "este es el cambio que contiene la noción de condición... tal es el processus de la realidad... cuando todas las condiciones se encuentran reunidas, la cosa debe realmente existir. Pero la cosa es ella misma una condición, porque, en cuanto cosa interior, no es sino una presuposición" "VIII. También Darwin hablaba del medio natural como una condición de la evolución humana ${ }^{\mathrm{IX}}$.

Engels define la economía política como la "ciencia de las condiciones y formas bajo las cuales las diversas sociedades humanas produjeron". Aseverando también: "son los mismos hombres los que hacen su historia, aunque dentro de un medio dado que los condiciona" . Mediante el término condiciones los creadores del marxismo introducen un tiempo y un espacio, en concreto, entre los conceptos fundamentales y abstractos del materialismo histórico, enfatizando, cómo no, las condiciones de producción ${ }^{\mathrm{XI}}$. Dentro de las cuales, distinguen tres tipos: condiciones estrictamente económicas, condiciones naturales y condiciones históricas, que actúan sobre las primeras, y viceversa. Puesto que la variedad de la condiciones naturales e históricas, inciden sobre los modos, las fuerzas, los medios y las relaciones de producción, generando la diversidad nacional. Podemos hablar luego de condiciones nacionales de producción como la base material e histórica del hecho nacional, según Marx y Engels, que desmintieron así la concepción hiper subjetivista de la nación predominante en el siglo XIX (regresa, hoy en día). Poniendo del revés una vez más la posición idealista de Hegel, con quien coincidían, no obstante, en la historicidad del fenómeno nacional: "los pueblos se suceden, surgen y desaparecen... el espíritu del pueblo es un individuo natural, como tal florece, madura, decae y muere"XII. Discrepando naturalmente en que hubiese un imaginario pueblonación "portador del concepto supremo"XIII, soporte elegido por la hegeliana Idea universal que guía la Historia. Para Marx los sujetos fundamentales de la historia son, en primer lugar, las clases sociales que emanan de las condiciones en que se realiza el proceso de producción y reproducción de la existencia humana, $\mathrm{y}$, en segundo lugar, las naciones para él siempre más terrenales, sociales e históricas que espirituales, elitistas y atemporales.

De forma que el modo de producción "abstracto y general" origina las clases sociales y las "concretas" condiciones de producción las naciones, y no se pueden entender las unas sin las otras, por mucho que las clases sean más universales que específicas y las naciones más específicas que universales. El modo de producción engendra la lucha de clases, y la lucha espacial e histórica por las condiciones de producción da lugar a las luchas entre las naciones. De la economía surgen las clases mientras que la sociedad civil se divide en naciones, constituidas a su vez por clases sociales.

Marx, analizando el comienzo de la división del trabajo, escribió: "Diversas comunidades descubren en la naturaleza circundante diversos medios de producción y diversos medios de sustento. Por tanto, su modo de producción, su modo de vivir y sus productos varían. Estas diferencias naturales son las que, al entrar en contacto unas 


\section{EL CONCEPTO MARXISTA DE NACIÓN ${ }^{1}$}

\section{CARLOS BARROS}

comunidades con otras, determinan el intercambio... la división social del trabajo surge por el cambio entre órbitas producción originariamente distintas pero independientes las unas de las otras"XIV . Aplicable, en diferente grado, tanto a la prehistoria comunitaria como a la historia nacional.

El marxismo fundacional aplica el término nación y afines a todas las épocas históricas, si bien dedicaron más atención a la nación burguesa. Hacen surgir las naciones, junto con las clases sociales, en el tránsito de la prehistoria a la historia, del modo comunitario de producción a la familia, la propiedad privada y el Estado. Escribió Engels en 1883: "en ciertas comarcas, tribus que fueran parientes en su origen y separadas después, se reunieron de nuevo en federaciones permanentes, dando así el primer paso para la formación de la nación" $\mathrm{XV}$.

Una mentalidad nacional verdaderamente abstracta, "indiferente" a las relaciones de clase y tendente a la larga duración, donde los hombres se abstraen de sus situaciones individuales tomando conciencia de sus intereses comunes frente a terceros, solo puede ser una realidad completa en un modo producción en el que los hombres figuren como iguales siendo desiguales. Tener conciencia de los intereses comunes alcanza por consiguiente en el capitalismo su desarrollo máximo, es lo que Marx y Engels suelen denominar la nación moderna. Prevé asimismo Engels en la etapa socialista -proféticamente- la existencia de una nación proletaria, así como la posibilidad de guerras defensivas contra "naciones anti-comunistas"XVI. Es menos taxativo el compañero de Marx cuando habla de una hipotética sociedad sin clases ni Estados, autoorganizada en comunas, si bien reconoce que persistirán en el comunismo desigualdades espaciales y naturales en las condiciones de producción y no deja de seguir utilizando los términos naciones, regiones y localidades: "De un país a otro, de una región a otra, incluso de un lugar a otro, existirá siempre una cierta desigualdad en cuanto las condiciones de vida, que podrán reducirse el mínimo, pero jamás suprimirse por completo. Los habitantes de los Alpes vivirán en condiciones distintas que los habitantes de la llanura"XVII.

Hemos encontrado muchas referencias, implícitas y explícitas, de Marx y Engels sobre el hecho nacional en textos teóricos y metodológicos como Ideología alemana (1849), Introducción de 1857, Grundisse (1857), Capital (1867), Dialéctica de la naturaleza (1875-76), Anti-Dühring (1878)..., que hemos contrastado con artículos periodísticos publicados en Nueva Gaceta Renana (1848-1849) y Nueva York Daily Tribune (1851-1852) y otros impresos "efímeros", junto con cartas a terceros que, tanto Marx como Engels, cultivaron hasta el final de sus vidas. Escritos de historia inmediata que contribuyeron no poco, empíricamente, a la elaboración y evolución de su concepto materialista de la nación, que inspiró de manera subyacente sus análisis de actualidad.

Los creadores del marxismo trataron de forma específica los procesos nacionales vividos en su tiempo: la formación de Francia, la unificación de Alemania, la restitución de Polonia, la liberación de Irlanda, la colonización de India y China, así como los avatares de los pueblos eslavos (Engels) ${ }^{\mathrm{XVIII}}$. Solían argumentar en cada caso su toma de posición política, inmediata, entrelazando magistralmente condiciones económicas, naturales e históricas, generales y particulares, previas y resultantes -posteriores a la acción humana-, internas y externas, aventurando conclusiones a menudo audaces sobre la viabilidad o inviabilidad de los diferentes proyectos nacionales y justificando, desde el punto de vista del proletariado como "clase nacional" y "clase internacional", sus propuestas para la liberación nacional de las naciones oprimidas o la promoción de 


\section{EL CONCEPTO MARXISTA DE NACIÓN ${ }^{1}$}

\section{CARLOS BARROS}

aquellas naciones más progresistas, combatiendo de continuo a las naciones más reaccionarias. Se concluye del estudio de estos textos de ocasión, tres cosas: la temporalidad del fenómeno nacional, la nación como una totalidad concreta, y que no se puede entender el concepto sin la combinación de las dimensiones objetiva y subjetiva de cada historia nacional, junto con su variable contexto internacional.

El problema nacional estuvo omnipresente a principios del siglo XX en la Rusia zarista. A partir de la Revolución de 1905, el Imperio ruso vive "el despertar del nacionalismo en las naciones oprimidas"XIX, lo que reclama la atención del naciente POSDR (bolchevique). Escribe sobre el tema V. I. Uliánov Lenin (Notas críticas sobre la cuestión nacional, 1913; El derecho de las naciones a la autodeterminación, 1914), desde un punto de vista político y opuesto al nacionalismo gran ruso. También Stalin (El marxismo y la cuestión nacional, 1913), con pretensiones más teóricas. Aunque el más madrugador fue Ber Borojov (La cuestión nacional y la lucha de clases, 1905), ucraniano, marxista y sionista de izquierda, quien ulteriormente ingresó con su partido (Poale Zion) en el Partido Bolchevique: participa en la Revolución de Octubre y muere de enfermedad en diciembre de 1917 a los 36 años. Su mayor mérito es haber dado cierta continuidad a las aportaciones teóricas de Marx y Engels sobre el hecho nacional a partir del concepto condiciones de producción. Si bien será Stalin, Comisario para las Nacionalidades en el primer Gobierno soviético (1917) y después omnímodo secretario general del PCUS (1922-1953), quien acaba por monopolizar el discurso marxista sobre la nación, incluso después de su desaparición física.

Borojov, pese a no haber llegado a conocer obras esenciales para el tema que nos ocupa como la Ideología alemana, los Grundisse o la Dialéctica de la naturaleza, además de artículos y cartas, resume a su manera, didácticamente, las posiciones de los fundadores del marxismo: 1) "La humanidad está dividida en sociedades"; 2) "En el concepto de condiciones de producción tenemos un firme punto de partida para construir una teoría puramente materialista de la cuestión nacional"; 3) "Una sociedad dada... necesita, ampliando la esfera de sus condiciones de producción, conquistar condiciones ajenas... unos anhelan conquistar, otros buscan defender... tiene lugar una lucha nacional" $\mathrm{XX}$.

Su apuesta personal en favor de una solución territorial al problema judío y el citado acceso restringido a las fuentes, pudo condicionar y limitar sus planteamientos, haciéndose merecedor de justas críticas por: a) su tendencia al natural-determinismo cuando aplica la noción "condiciones de producción"; b) la no consideración de la base económica como parte fundamental, "desde el interior", de las condiciones de producción; c) la separación de lucha de clases de la lucha de naciones, ignorando su base económica común; d) el olvido de que las condiciones de producción son también de reproducción social ${ }^{\mathrm{XXI}}$, razón de ser de la lucha de las naciones por las condiciones de producción. Así y todo, su obra supone un antes y un después en el necesario proceso de recuperación de un enfoque materialista, histórico y dialéctico del concepto de nación.

Paralelamente, se va imponiendo a lo largo del siglo XX, desde la Unión Soviética y la Internacional Comunista, la contribución de Iósif Stalin -que ignora, por supuesto, los trabajos del judío Borojov- sobre el concepto de nación de una forma más descriptiva que explicativa, más política que teórica, desconectada de los esfuerzos previos de Marx y Engels por incluir la nación, junto con la clase y el Estado, entre las categorías esenciales del materialismo histórico. 


\section{EL CONCEPTO MARXISTA DE NACIÓN ${ }^{1}$}

\section{CARLOS BARROS}

La aportación conceptual de Stalin gira alrededor de una definición de nación, pensada para justificar el derecho o no a la libre determinación, basada en una breve y limitada definición que fija los rasgos necesarios para que una nación sea considerada como tal: "Nación es una comunidad humana estable, históricamente formada, surgida sobre la base de la comunidad de idioma, de territorio, de vida económica y de psicología, manifestada ésta en la comunidad de cultura... Sólo la presencia conjunta de todos los rasgos distintivos forma la nación"XXII. Lo último cierra la posibilidad de aprehender la variabilidad del hecho nacional en la historia, y excluye a la nación judía que no tendrá territorio propio hasta 1948 en Palestina.

Ciertamente Engels opinaba que "las definiciones no tienen ningún valor para la ciencia porque son siempre insatisfactorias. La única definición real es el desarrollo de la cosa misma, lo cual no es ya ninguna definición... En cambio, para el uso corriente puede que a menudo sea útil y necesaria una breve exposición de los caracteres más generales $\mathrm{y}$, al mismo tiempo, más identificadores que una sedicente definición, $\mathrm{y}$ tampoco puede perjudicar si no se pide de ella más de lo que se puede decir"XXIII. No fue así, de la definición descriptivista de Stalin, no muy distinta de la que se manejaba en aquel tiempo por parte de la Sociedad de las Naciones, se quiso hacer una teoría cerrada, pidiendo "de ella más de lo que se puede decir", orillando por tanto "el desarrollo de la cosa misma" que tanto buscaron Marx y Engels, y tempranamente reconoció Borojov.

Hay que tener en cuenta que la elaboración de Stalin tuvo lugar cuando se luchaba por un POSDR (bolchevique) único, con autonomías territoriales para las socialdemocracias nacionales, en oposición al federalismo del Bund y a la reivindicación de autonomía cultural-nacional por parte de nacionalistas judíos y un sector de los socialdemócratas caucasianos "que no pudieron resistir a la 'epidemia' nacionalista"XXIV. Por esas mismas razones ataca Stalin, en su texto de 1914, al austromarxismo: "La autonomía cultural-nacional de Springer [Karl Renner] y Bauer es una sutil variedad del nacionalismo", enfrentándose a la proposición de Otto Bauer "evolutivo-nacional" de "adaptar la lucha de clases de los obreros a la lucha de naciones"XXV . Cosa, por otro lado, que ya habían preconizado en su momento Marx y Engels en los casos de Polonia e Irlanda ${ }^{\mathrm{XVI}}$.

Stalin critica también a Otto Bauer, ahora justamente, por considerar el carácter nacional como "único rasgo esencial de la nación", insistiendo en que es "reflejo de las condiciones de vida..., del medio circundante", pero acaba paradójicamente relegando las "condiciones económicas" a un elemento más de los que definen o describen la nación $^{\text {XVII }}$, a diferencia de lo defendido con gran insistencia por Marx y Engels acerca de la hegemonía de las condiciones de producción.

Emmanuel Terray adopta, en 1973, una postura muy beligerante contra el aporte de Stalin, descalificando como empirista su definición nacional y reprobando su arbitrariedad en cuanto al número y la asociación de los rasgos inventariados, así como la exclusión de las naciones que no cumplen los siete criterios distintivos, asegurando por último que la definición de Stalin conduce a considerar la nación como una esencia ahistórica y proponiendo su "fórmula" para romper con el esquematismo estalinista: "reintroducir en la definición de nación la distinción de los factores objetivos y de los factores subjetivos", caracterizados en su relación dialéctica y potenciando además la idea (que viene del marxismo original y fue estrenada en la Revolución francesa) de la nación como sujeto social: bloque de clases que se constituye en nación en un momento dado XXVIII. 


\section{EL CONCEPTO MARXISTA DE NACIÓN ${ }^{1}$}

\section{CARLOS BARROS}

En el marco de la renovación del marxismo occidental con posterioridad a Mayo del 68, se retoman pues diversos aspectos del marxismo fundacional en lo tocante al estatus teórico de la nación. Pierre Vilar, entre otros, recobra la nación como categoría presente en todas las épocas históricas, no solamente durante la Edad Contemporánea y ligada al capitalismo ascendente, como defendía Stalin ${ }^{\mathrm{XXIX}}$. Lo mismo el último Nicolás Poulantzas que utiliza además sin nombrarlo (el marxismo estructuralista lo marginará) el concepto de condiciones de producción y de reproducción: "la nación no se identifica con la nación moderna y el Estado nacional, tal como aparece en la emergencia del capitalismo en Occidente. Hay 'algo' que se designa bajo el término de nación, es decir, una unidad particular de reproducción del conjunto de relaciones sociales, mucho antes del capitalismo" XXX .

Echamos en falta en los años 80, con todo, una recuperación cabal de las aportaciones de Marx y Engels, inspirados en la intuición de Borojov, que hemos intentado llevar a buen puerto, en 1985, con motivo del I Centenario de la muerte de Karl Marx $^{\mathrm{XXI}}$. La ulterior crisis del marxismo, acelerada por la transición del "socialismo realmente existente" al capitalismo liberal en la Unión Soviética, la República Democrática Alemana y el Este de Europa, dejó en suspenso, en el ámbito académico y político, la necesaria actualización de las categorías del materialismo histórico en un mundo en mutación de forma crítica y autocrítica, incluida el concepto de nación, que hoy conmina a volver a los clásicos del marxismo, a fin de implementar herramientas y nociones realmente materialistas y globales, discriminando en cualquier caso sus aciertos y errores, vigencias, caducidades y nuevas realidades.

Siglo y medio después de Marx y Engels precisamos de su metodología y enfoque nacional/internacional para afrontar con éxito el "desarrollo de la cosa misma", aplicado al hecho nacional, que adquiere una mayor complejidad y pluralidad en comparación con los tiempos del Estado-nación e inicios del Imperialismo que ellos vivieron. El formidable salto de las fuerzas productivas como consecuencia de la revolución de la ciencia y la técnica entre el siglo XX y el siglo XXI, ha causado unas relaciones supranacionales para la producción, la comunicación y el comercio nunca vistas, que venimos denominando globalización y afecta a todas las dimensiones de la existencia humana, obligándonos a replantearse los viejos conceptos de clase, nación y Estado, entre otros.

Las nuevas condiciones globales de producción del siglo XXI han originado tres tipos de naciones, en proceso de construcción y/o reformulación: 1) nacionalidades medievales y etnias pre-coloniales que renacen por efecto de la mundialización; 2) Estados-naciones hoy en declive, después de haber dominado las Edades Moderna y Contemporánea; 3 ) nuevos e incompletos fenómenos macronacionales producto directo de los inéditos ámbitos transnacionales de cooperación, integración y comunicación, al calor de la globalización económica, social y cultural, como la Comunidad Europea y la misma Comunidad Mundial, en diferentes niveles de institucionalización y soberanía política $^{\text {XXXII }}$.

Durante los siglos XIX y XX los procesos de producción y reproducción social fueron incapaces de organizarse de manera plena en una órbita planetaria: tenían lugar, pese a los intercambios comerciales entre países, en órbitas nacionales excluyentes que limitaban entre sí. La concomitancia dialéctica de la unificación / diversificación en las nuevas condiciones generales de producción hace ahora que los fenómenos nacionales se desarrollen en círculos inclusivos. Lo normal en el siglo XXI es que una nación sea un subconjunto de otra comunidad mayor de tipo asimismo nacional. La superposición de diferentes tipos de comunidades nacionales trae como consecuencia la doble o la 


\section{EL CONCEPTO MARXISTA DE NACIÓN ${ }^{1}$}

\section{CARLOS BARROS}

triple nacionalidad del individuo, proceso unificador-diversificador está todavía en sus comienzos $^{\text {XXXIII }}$. A lo que debemos añadir que la presente universalización de valores tiende a reconocer, paralelamente, la diversidad étnica y nacional como parte capital del patrimonio colectivo histórico, cultural y político mundial.

En resumen, cada nivel de los procesos nacionales en curso, o cada caso particular de nación, requiere un estudio a la manera de Marx y Engels de las condiciones económicas, naturales e históricas de producción y reproducción, materiales y culturales, objetivas y subjetivas, generales y particulares, internas y externas, previas y resultantes, que determine su cualidad, viabilidad e interés desde una óptica de progreso, de forma que se sustenten con mayor rigor los programas en marcha de liberación, recuperación o integración nacional, las críticas a los otros ciudadanos nacionales, así como las paradojas de las nacionalidades superpuestas. Considerando que, hoy por hoy, los criterios de posicionamiento nacional suelen basarse, con harta frecuencia, en la ideología, la improvisación o las emociones, el pensamiento científico y político del siglo XXI daría un gran salto adelante en la comprensión de lo nacional, gracias a dos viejos pero actuales científicos sociales: Karl Marx y Friedrich Engels.

\footnotetext{
I Versión castellana del artículo sobre "Nationale Identität" preparado para el tomo 11 de Diccionario Histórico-Crítico del Marxismo de Berlín (Historisch-kritisches Wörterbuch des Marxismus, Bd. 9/II: Mitleid bis Nazismus, Argument-Verlag, Hamburg 2020).

"Director-Fundador de la Red Académica Internacional Historia a Debate. Profesor de Historia Medieval e Historiografía de la Universidad de Santiago de Compostela. Más información en: www.cbarros.com y www.h-debate.com.

III El vocablo 'identidad' se utiliza asimismo con otras colectividades definidas como etnias, géneros o grupos de orientación sexual.

IV Manifiesto comunista, OME, 9, pp. 154-155.

V Según la edición de Engels de 1888: "la clase dirigente de la nación".

VI Materiales para el Anti-Dühring, OME, 35, Barcelona, 1977, p. 340.

VII Los prejuicios explican en parte cierto abandono teórico de la "cuestión nacional" por parte del marxismo, Georges HAUPT, y Michael LÖWY, Los marxistas y la cuestión nacional, Barcelona, Editorial Fontamara, 1980, p. 11; Robert STUART, Marxism and National Identity. Socialism, Nationalism and National Socialism during the French Fin de Siècle, NY, State University of New York Press, 2006, p. 2.

VIII HEGEL, Lógica, Madrid, 1971, pp. 243 ss.

IX Dialéctica de la Naturaleza, OME, 36, pp. 324-325.

${ }^{\mathrm{X}}$ Engels a Starkenburg, 25-1-1894, OE, 2, Akal, p. 359; Engels a Bloch, 21/22-9-1890, OE, 2, p. 521; Anti-Dühring, OME, 35, p. 154.

${ }^{\mathrm{XI}}$ Hemos abordado el tema con mayor detenimiento en Carlos BARROS, "A base material e histórica da nación en Marx e Engels", Dende Galicia: Marx. Homenaxe a Marx no $1^{\circ}$ centenario da súa norte (Carlos Barros, José Vilas Nogueira, eds.), A Coruña, 1985, pp. 172 ss. (trad. español en https://cbarros.com/la-base-material-e-historica-la-nacion-marx-engels/).

${ }^{\mathrm{XII}}$ HEGEL, Lecciones sobre la filosofia de la historia universal, Madrid, Alianza Universidad, 1982, pp. $69,71$.

XIII Ibidem, p. 73.

XIV Capital, 1, p. 286; véase también N.I. BUJARIN, Teoría del materialismo histórico, Madrid, 1974, pp. 191-193.

XV ENGELS, El origen de la familia, la propiedad privada, y el Estado, Madrid, 1972, p. 94.

XVI ENGELS, “Discursos en Elberfeld”, La sociedad Comunista, Madrid, 1976, pp. 11-15.

XVII Engels a Babel, 18/28-3-1875, OE, 2, p. 36.

XVIII BARROS, Carlos op. cit., pp. 155-170.

XIX LENIN, El derecho de las naciones a la autodeterminación, 1914 (https://www.marxists.org/espanol/lenin/obras/1910s/derech.htm)

XX BOROJOV, "Los intereses de clase y la cuestión nacional", Nacionalismo y lucha de clases, México, 1979, pp. 57-63.
}

Cadernos do Tempo Presente, São Cristóvão-SE, v. 11, n. 02, p. 27-35, jul/dez. 2020||

http://www.seer.ufs.br/index.php/tempo 


\section{EL CONCEPTO MARXISTA DE NACIÓN ${ }^{1}$ \\ CARLOS BARROS}

XXI GALLISSOT, René. "Contra el fetichismo", El concepto de "formación económico-social", p. 182; "Nación y nacionalidad en los debates del movimiento obrero", Historia del marxismo, 4, Barcelona, 1981, p. 26.

XXII STALIN, El marxismo y la cuestión nacional, Madrid, 1976, p. 25.

XXIII Materiales para el Anti-Dühring, OME, 35, p. 344.

XXIV STALIN, op. cit. pp. 77, 94-98.

XXv Ibidem, pp. 39, 59.

XXVI "Marx a Engels", 10-12-1869, Imperio y Colonia. Escritos sobre Irlanda, México, 1979, p. 193; "Engels a Kautsky", 7-12-1882, El marxismo y la cuestión nacional, p. 36.

XXVII STALIN, El marxismo y la cuestión nacional, Madrid, 1976, pp. 25-29.

XXVIII TERRAY, E. "La idea de nación y transformaciones del capitalismo", El marxismo y la cuestión nacional, Barcelona, 1977, pp. 151-157 (ed. orig. Les temps modernes, n. 324-326, agosto-septiembre 1973).

XXIX VILAR, P. La Cataluña en la España moderna, Barcelona, 1978, p. 47 (edición original, París, SEVPEN, 1962); "Sobre los fundamentos de las estructuras nacionales", Historia 16, abril 1978, pp. 1416; Iniciación al vocabulario de análisis histórico, Barcelona, 1980, pp. 183-185; "Stalin i la questió nacional”, Nous Horizons, n. 63, maig 1980, pp. 11-13.

XXX Nicos POULANTZAS, Estado, poder y socialismo, Madrid, Siglo XXI, 1978, p. 109.

XXXI Carlos BARROS, "A base material e histórica da nación en Marx e Engels", Dende Galicia: Marx, A Coruña, 1985, pp. 139-207 (trad. español en https://cbarros.com/la-base-material-e-historica-la-nacionmarx-engels/).

XXXII BARROS, Carlos. "Los fines de la historia en el siglo XXI", Historia Actual Online, Cádiz, n 45, Invierno 2018, pp. 147-155 (http://cbarros.com/fines-de-la-historia-en-el-siglo-xxi/).

XXXIII Lo vaticinamos en $A$ base material e histórica da nación en Marx e Engels, Santiago de Compostela, 1985, p. 193. 